\title{
Patients' Preferences on Different Types of Esthetic Treatment in Saudi Arabia
}

\author{
Fatima L Al Otaibi ${ }^{1}$, Ahmed F Althumairy², Budur T Al Ahmadi ${ }^{3}$, Nouf M Alkhamis ${ }^{4}$
}

\begin{abstract}
Aim: Dental cosmetics have always had a large-scale impact on an individual's social life. A variety of dental treatment regimens ranging from composite resins to ceramics are available to enhance the oral esthetic appearance.

Materials and methods: The present study aimed to identify the preferred dental cosmetic treatment regimen used in Saudi Arabia. The sample included 434 patients, who were asked to mention their preferred esthetic treatment. A close-ended, predesigned questionnaire was used to collect the data. The questionnaire was made using the survey monkey which was distributed to the study participants using social networking sites like WhatsApp and E-mail. The response data were analyzed using SPSS.

Results: Out of 434 respondents included in the study, 140 were males and 294 were females. The majority of the participants had taken some form of esthetic dental treatment $(n=230)$; of these composite buildups were the most common $(n=132)$, followed by bleaching $(n=$ $84)$, veneers ( $n=31$ ) and prepless veneers (lumineers) ( $n=11)$. It was noted that a majority of the surveyed population preferred permanent treatment modalities $(n=304)$ rather than temporary treatment strategies $(n=33)$.

Conclusion: A significant proportion of participants preferred taking permanent treatment over the temporary treatment regimens.

Clinical significance: Understanding patient's perception regarding their dental esthetics helps the clinicians to plan treatments which are patient compliant and elicits a higher level of therapeutic satisfaction.

Keywords: Bleaching, Esthetic treatment, Veneers, Whitening.

The Journal of Contemporary Dental Practice (2020): 10.5005/.jp-journals-10024-2714
\end{abstract}

\section{INTRODUCTION}

Every individual aspires to have the best appearance for their lifetime. A beautiful smile not only changes the esthetics but also builds confidence. Cosmetic dentistry aims to bring in a positive change both in the smile and personality. One of the most popular dental cosmetic procedures available is tooth bleaching. Nowadays many patients prefer it to make their teeth look whiter. There are several options available for esthetic treatments; professionals have alternatives ranging from composite resins to ceramics. In the past, the composite resin was the material of choice for cosmetic and conservative procedures. ${ }^{1}$ Low durability and need for constant maintenance led the search for a better esthetic option. ${ }^{2}$ Porcelain is an outstanding option to avoid the numerous deficiencies of composite resin, and it significantly mimics the natural structure of dental foundations. ${ }^{3}$ When properly made in accordance with a precise clinical protocol, porcelain restorations have a long clinical life. Nowadays, development in adhesive technologies has made possible a variety of more conservative restoration techniques. ${ }^{2-4}$ One among them was the minimal or virtually no preparation veneers. But the lack of clarity regarding the extent of veneer preparation creates miscommunication with patients and also within the dental profession.,

Numerous bleaching modalities are available for dental treatment like in-office bleaching, at-home bleaching, over-thecounter or combination technique either on vital or nonvital teeth. ${ }^{7,8}$ In-office bleaching is usually done using different concentrations of hydrogen peroxide bleaching agent (15\%, 30\%, or 35\%) either heated or nonheated. Protection of soft tissue by using gingival dam gel is mandatory to avoid burning of gum. The merits of this technique are that it shows faster results and not having to wear the tray as in as at-home bleaching. ${ }^{9,10}$ In-home bleaching, dentist needs
${ }^{1}$ Restorative Department, Riyadh Elm University, Kingdom of Saudi Arabia

${ }^{2}$ Ministry of Health, Jouf, Tabarjal, Kingdom of Saudi Arabia

${ }^{3}$ Prince Sultan Medical Military City, Alandalus District, Riyadh, Kingdom of Saudi Arabia

${ }^{4}$ Riyadh Elm University, Al hamra District, Riyadh, Kingdom of Saudi Arabia

Corresponding Author: Fatima L Al Otaibi, Restorative Department, Riyadh Elm University, Kingdom of Saudi Arabia, Phone: +966 553960066, e-mail: fatima.alotaibi@riyadh.edu.sa

How to cite this article: Al Otaibi FL, Althumairy AF, Al Ahmadi BT, et al. Patients' Preferences on Different Types of Esthetic Treatment in Saudi Arabia. J Contemp Dent Pract 2020;21(1):62-67.

Source of support: Nil

Conflict of interest: None

to take impression of teeth which is sent to laboratory to obtain a model. A special custom tray made of plastic (night guard) is used, on to which $10 \%$ carbamide peroxide (ADA), or $6-15 \%$ hydrogen peroxide is applied. ${ }^{9-12}$ Combination treatment refers to the use of both techniques; in-office followed by at-home bleaching for 5 days for better results which also reduces chair time. ${ }^{9}$

Failure in esthetic treatments has been reported in recent years. In a 12-year retrospective survey, the most common complication noted (48\%) was fracture. ${ }^{13-15}$ On the other hand, another study reported $93 \%$ of the sample had intact clinical survival of tooth structure, bonding to enamel, color stability and overall good esthetics even after 15 years. ${ }^{14}$ For conservative treatment, PLV is the chosen method, especially in the anterior teeth. ${ }^{13-15}$ It is an ultra-thin technique which allows the dentists to remove only $0.3 \mathrm{~mm}$ of tooth 
structure. ${ }^{16}$ A meta-analysis published in 2013 reported that the preparation design determines the outcome of the treatment. ${ }^{17,18}$ To gain high esthetic and functional restorations, the mechanical resistance of porcelain veneers is of great importance. ${ }^{19,20}$ The longevity and the success of the porcelain veneers depend on better stress distribution. ${ }^{21-23}$ Very few studies have focused on the impact of the preparation design, on the success and durability of the restoration, and at the same time, there are some very controversial results. ${ }^{24-26}$ The success of anterior indirect restoration depends on proper treatment planning and application of the operative protocol. ${ }^{27}$

Ceramic veneers involving the incisal edge, proximal areas and larger parts of the palatal surface have been recognized as an alternative to full crowns in the anterior dentition. ${ }^{28,29}$

In the direct veneering technique, the composite resin is applied directly to tooth structure and artistically scalped to correct color and contour defects. ${ }^{30,31}$ The successful esthetic and functional results are dependent primarily on the operator's understanding of adhesive technology and the components of color, including their relationship to natural tooth structure and composite resin restorative materials. ${ }^{32-35}$ The aim of this study was to analyze the preferences of the patients towards esthetic treatments and to identify potential factors influencing their choices.

\section{Materials and Methods}

A cross-sectional questionnaire (see Appendix) study was designed to evaluate patient's preferences toward esthetic treatment in Saudi Arabia. This was a cross-sectional study done on patients above 18-year of age.

A pilot study was conducted on 20 patients to assess the reliability of the questionnaire. This was tested using Cronbach's alpha coefficient. A definitive questionnaire was then prepared, which was sent to all the participants. Variables elicited were satisfaction with dental esthetics, cause of dissatisfaction, any previous dental esthetic treatment experience, type of treatment obtained and preference and any complications faced during or after the treatment.

Informed consent was obtained from the Institutional Review Committee of Riyadh Elm University. The study was conducted between February 2019 to July 2019 for 6 consecutive months, employing a convenient sampling technique, selecting both males and females. The participants were patients attending OPD of Riyadh Elm University.

Informed consent was obtained from all respondents after explaining the purpose of the study. Individuals below 18-year were not included in the study.

The empirical sample size determination was employed to determine the sample size, which came up to 390 . Considering a nonresponse rate of $10 \%$, a sample of 434 was finalized for the study. The questionnaire was sent along with photos sent through emails.

A five-point Likert scale was used to evaluate attitude related questions in evaluating perception of patients ranging from 0 being most negative and four ratings to be most positive.

The data so obtained were transferred to spreadsheets and analyzed using SPSS 19.0 version. A Chi-square test was used to evaluate patient's perceptions towards dental esthetic therapy.

\section{Results}

The sample comprised of 434 respondents (140 males and 294 females). A $100 \%$ response rate was obtained. The sample had significantly more Saudis $(n=421)$ compared to non-Saudis $(n=$ 13) (Chi-square 63.21, $p<0.001$ ). The sample comprised mainly of individuals in the 18-25 age group and 26-35 age group, including both males and females (Table 1). There was no significant difference noted in the numbers of males and females in either age group or nationality (Table 1).

The overall satisfaction with dental esthetics was measured on a Likert scale from 0 (most dissatisfied) to 4 (extremely satisfied). The overall satisfaction score was 2.36 (SD \pm 1.3 ). There was no significant difference between the satisfaction scores of the males and females (Table 2).

When the reasons for dissatisfaction were tabulated, dental stains topped as the most common cause for dissatisfaction. A great proportion of the sample $(n=188)$ did not specify their reason for dissatisfaction (Fig. 1).

The majority of the population had taken some form of esthetic dental treatment $(n=230)$. Of these, composite buildup was the most common ( $n=132)$, followed by bleaching $(n=84)$, veneers ( $n=31)$ and prepless veneers (lumineers) $(n=11)$. The majority of the surveyed population preferred permanent treatment $(n=304)$ to temporary treatment $(n=33)$. There was no significant difference between males and females in their experience of dental treatment (Table 3).

Table 1: Demographic profile of the sample

\begin{tabular}{|c|c|c|c|c|c|}
\hline & & \multicolumn{2}{|c|}{ Gender } & \multirow[b]{2}{*}{ Chi-square } & \multirow[b]{2}{*}{ Sig. } \\
\hline & & Male count & Female count & & \\
\hline \multirow[t]{4}{*}{ Age group } & $18-25$ years & 40 & 92 & 4.491 & 0.213 \\
\hline & $26-35$ years & 52 & 90 & & \\
\hline & $36-45$ years & 21 & 65 & & \\
\hline & $>45$ years & 27 & 47 & & \\
\hline \multirow[t]{2}{*}{ Nationality } & Saudi & 135 & 286 & 0.236 & 0.627 \\
\hline & Non-Saudi & 5 & 8 & & \\
\hline
\end{tabular}

Table 2: Comparison of overall satisfaction between males and females

\begin{tabular}{llllll}
\hline & Gender & Mean & Std. deviation & $T$ & Sig. \\
\hline Satisfaction with current dental & Male & 2.3286 & 1.12168 & 0.390 & 0.697 \\
esthetics & Female & 2.2823 & 1.17070 & & \\
\hline
\end{tabular}




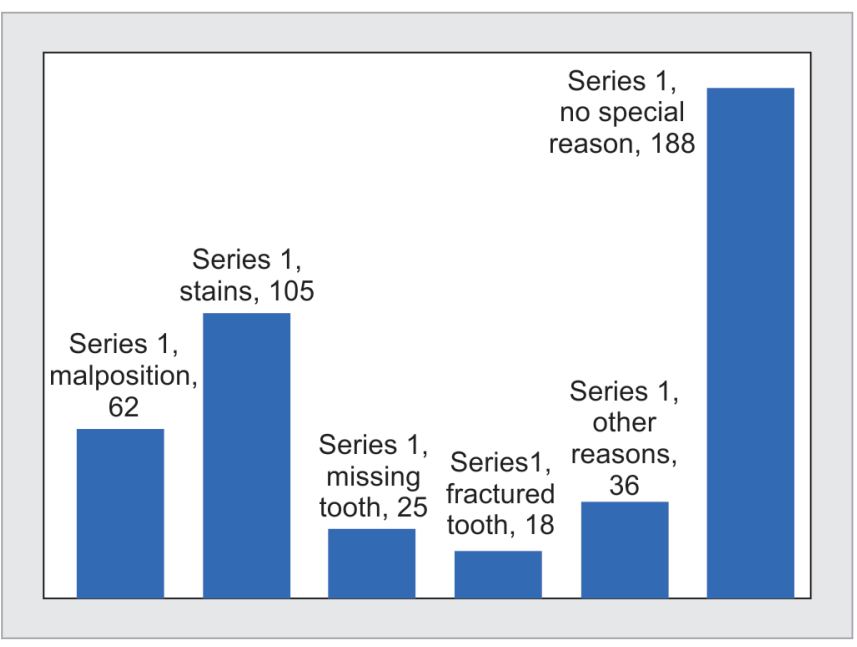

Fig. 1: Causes for dissatisfaction with esthetics
When complications following esthetic dental treatment were summarized, it was observed that 92 of the 159 participants who had undergone esthetic dental treatment reported some form of complication. The complications ranged from bad odor $(n=29)$ and sensitivity $(n=58)$ to serious complications such as swellings and abscess $(n=23)$. There were no significant differences in the incidence or pattern of complications between males and females (Table 4).

There were two questions in the survey pertaining to the attitude of the respondents towards dental treatment. These questions were scored on a five-point Likert scale with 0 being the most negative and 4 being the most positive. The scores for these questions were added to obtain an overall attitude score. This attitude score was used as the dependent variable in a regression model to analyze factors affecting the respondent's attitude towards esthetic dentistry (Table 5). The model showed that factors like person's gender (females more positive than males) regarding their perception of esthetics and previous history of

Table 3: Esthetic dental treatment experience of the surveyed population

\begin{tabular}{|c|c|c|c|c|c|}
\hline & & \multicolumn{4}{|c|}{ Gender } \\
\hline & & Male & Female & Chi-square & Sig. \\
\hline \multirow{2}{*}{$\begin{array}{l}\text { Underwent esthetic } \\
\text { treatment }\end{array}$} & No & 69 & 135 & 0.432 & 0.511 \\
\hline & Yes & 71 & 159 & & \\
\hline \multirow{4}{*}{$\begin{array}{l}\text { Type of esthetic } \\
\text { treatment }\end{array}$} & Composite buildup & 45 & 87 & 5.229 & 0.156 \\
\hline & Bleaching & 19 & 65 & & \\
\hline & Veneers & 12 & 19 & & \\
\hline & Prepless veneers (lumineers) & 5 & 6 & & \\
\hline \multirow{2}{*}{$\begin{array}{l}\text { Type of treatment } \\
\text { preferred }\end{array}$} & Temporary treatment & 7 & 26 & 1.255 & 0.263 \\
\hline & Permanent treatment & 93 & 211 & & \\
\hline
\end{tabular}

Table 4: Complications following esthetic treatment

\begin{tabular}{llllll}
\hline & & \multicolumn{3}{c}{ Gender } \\
\cline { 3 - 5 } & & Male & Female & Chi-square & Sig. \\
\hline Complications after & No & 74 & 150 & 0.408 & 0.523 \\
treatment & Yes & 27 & 65 & & \\
Type of complications & Sensitivity & 22 & 36 & 2.314 & 0.678 \\
& Bleeding from the gingiva & 3 & 10 & & \\
& Bad odor & 8 & 21 & & \\
& Swelling & 9 & 14 & & \\
& Broken restoration & 6 & 16 & & \\
\hline
\end{tabular}

Table 5: Regression model showing the attitude of the respondents towards esthetic dentistry ${ }^{\text {a }}$

\begin{tabular}{|c|c|c|c|c|c|c|}
\hline & & \multicolumn{2}{|c|}{$\begin{array}{c}\text { Unstandardized } \\
\text { coefficients }\end{array}$} & \multirow{2}{*}{$\begin{array}{c}\begin{array}{c}\text { Standardized } \\
\text { coefficients }\end{array} \\
\beta\end{array}$} & \multirow[b]{2}{*}{$T$} & \multirow[b]{2}{*}{ Sig.* } \\
\hline \multicolumn{2}{|c|}{ Model } & $\beta$ & Std. error & & & \\
\hline \multirow[t]{6}{*}{1} & (Constant) & 5.496 & 0.425 & & 12.934 & 0.000 \\
\hline & Age group & 0.155 & 0.079 & 0.111 & 1.957 & 0.051 \\
\hline & Gender & -0.414 & 0.176 & -0.132 & -2.351 & $0.019^{* *}$ \\
\hline & Satisfaction with current dental esthetics & -0.205 & 0.071 & -0.163 & -2.870 & $0.004^{* *}$ \\
\hline & Underwent esthetic treatment & 0.417 & 0.182 & 0.133 & 2.297 & $0.022^{* *}$ \\
\hline & Complications after treatment & -0.044 & 0.190 & -0.014 & -0.233 & 0.816 \\
\hline
\end{tabular}

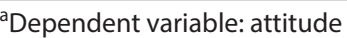

*Calculated using linear regression modeling

${ }^{*}$ Associations significant at $p<0.05$ 
esthetic treatment had a significant positive association with the overall perception of esthetic dental care. Gender and past history of complications following dental treatment had no significant association with the attitude towards esthetic dentistry.

\section{Discussion}

Out of the 434 subjects investigated, $67.7 \%$ were females and $32.2 \%$ males. Respondents were divided into four age groups for the sake of analysis. The first group was between 18 years and 25 years constituting $30.4 \%$, the second group was between 26 years and 35 years making $32.7 \%$, the third group was between 26 years and 35 years forming $32.7 \%$ and the last group was more than 45 years which formed $17.1 \%$ of the sample. Based on the study results, $56.7 \%$ (246 of subjects) of participants were not satisfied with their own smile for the following reasons: $42.7 \%$ (105 subjects) complained of dental stains; $25.2 \%$ (62 subjects) complained of malposition of teeth, $5.7 \%$ ( 25 subjects) had some kind of tooth loss, $4.1 \%$ (18 subjects) had fractured tooth and $8.3 \%$ of subjects cited other reasons like diastema, calculus or gum problem.

In this study, the percentage of study population who were dissatisfied with their esthetics was higher than studies of REU in KSA conducted by Aldaij et al. ${ }^{36}$ in which $44.5 \%$ of 1,147 subjects were not satisfied with dental appearance, ${ }^{36} 42.7 \%$ of 1,014 subjects dental school in Ankara, Turkey in the study of Akarslan et al. ${ }^{37}$ were dissatisfied with teeth appearance, and $38.4 \%$ of 1,129 subjects who were not satisfied with their smile in a study conducted by Majed et al. ${ }^{38}$ The same findings were reported in yet another study conducted in Tamil Nadu, India by Thiyagarajan et al. ${ }^{39}$ wherein, 31\% of 206 subjects were not confident with their smile. ${ }^{39}$

Most of the studies conducted in this regard were consistent with our study findings of obtaining no significant difference between esthetic satisfaction scores between males and females. The Likert scale was chosen to evaluate the response owing to its ease of use.

In our sample, $29.1 \%$ reported that they suffered from some sort of complication following their esthetic treatment. This number represents a much higher percentage in comparison with the majority of previous studies, where the reported complications ranged from 4 to $7 \% .^{40-44,49}$ The higher complication rate in our sample could be explained by many factors that were not assessed in our study, and have been shown to have significant effect on the outcome of the treatment. Those factors include the design of the restoration, proper dental preparation, the use of conventional treatment as opposed to the all-ceramic restorations, type of ceramics, the experience of the operators, and bruxism habits. ${ }^{40,41,45-48}$ Another aspect of the complications that were not assessed was their timing after the treatment because it has been reported that failures increase from $5 \%$ at 5 years and remain well under $10 \%$ at $10-13$ years. ${ }^{48}$ Lastly, many studies assessing the survival of the restorations and the complications rate do differentiate between failures such as fractures, and complications such as hypersensitivity. ${ }^{40,41,49}$ Almost half of the reported complications in our sample were due to hypersensitivity $53.1 \%$, followed by bad odor $31 \%$, swelling $18.6 \%$, broken or fallen down $17.9 \%$ and lastly followed by bleeding in $17.2 \%$. In a previous study, sensitivity was experienced by patients only in the first 2 weeks, ${ }^{44}$ and the rest of the complications needed further questioning to clarify their effect on the treatment.

In our study $71.8 \%$ of our study participants recommended the use of dental esthetic treatment. This is in concordance with the reported increasing trend of using veneers. ${ }^{52}$ Although previous national studies reported low knowledge and awareness of veneers, ${ }^{50,51} 86.9 \%$ of our sample chose veneers as a favorite choice for esthetic treatment.

The study result gives an overall view of the patient's perception of dental esthetic treatment but has to be interpreted with caution because it does not represent the whole population of this age group.

\section{Conclusion}

Based on the results that were obtained from our research, we concluded that majority of the participants preferred permanent treatment over the temporary one; unlike for prepless veneer which got very few responses. A greater number of female participants got esthetic treatments than male participants. A major proportion of the sample $(n=188)$ did not specify their reason for dissatisfaction $(n=188)$.

\section{References}

1. Agustín-Panadero R, Solá-Ruíz MF. Vertical preparation for fixed prosthesis rehabilitation in the anterior sector. J Prosthet Dent 2015;114(4):474-478. DOI: 10.1016/j.prosdent.2015.05.010.

2. Coldea A, Swain MV, Thiel N. Mechanical properties of polymerinfiltrated-ceramicne work materials. Dent Mater 2013;29(4):419-426. DOI: 10.1016/j.dental.2013.01.002.

3. Gürel G. Porcelain laminate veneers: minimal tooth preparation by design. Dent Clin North Am 2007;51(2):419-431. DOI: 10.1016/ j.cden.2007.03.007.

4. Javaheri D. Considerations for planning esthetic treatment ith veneers involving no or minimal preparation. J Am Dent Assoc 2007;138(3):331-337. DOI: 10.14219/jada.archive.2007.0165.

5. Spitzangel FA, Horvath SD, Guess PC, et al. Resin bond to indirect composite and new ceramic/polymer materials: a review of the literature. J Esthet Restor Dent 2014;26(6):382-393. DOI: 10.1111/ jerd.12100.

6. Spear F, Holloway J. Which all-ceramic system is optimal for anterior for anterior esthetics? J Am Dent Assoc 2008;139(Suppl):19S-24S. DOI: 10.14219/jada.archive.2008.0358.

7. Leonard RH, Jr., Smith LR, Garland GE, et al. Evaluation of side effects and patients' perceptions during tooth bleaching. J Esthetic Restor dentistry: Off Publ Am Acad Esthetic Dent 2007;19(6):355-364. DOI: 10.1111/j.1708-8240.2007.00136.x; discussion 65-6.

8. Greenwall-Cohen J, Greenwall LH. The single discoloured tooth: vital and non-vital bleaching techniques. Br dental J 2019;226(11):839-849. DOI: 10.1038/s41415-019-0373-9.

9. Kihn PW. Vital tooth whitening. Dent Clin North Am 2007;51(2): 319-331. DOI: 10.1016/j.cden.2006.12.001, viii.

10. Martini EC, Parreiras SO, Szesz AL, et al. Bleaching-induced tooth sensitivity with application of a desensitizing gel before and after in-office bleaching: a triple-blind randomized clinical trial. Clin oral investigations 2019. DOI: 10.1007/s00784-019-02942-9.

11. Martini EC, Parreiras SO, Acuna ED, et al. Does the use of reservoirs have any impact on the efficacy of at-home bleaching? A systematic review. Braz dental J 2019;30(3):285-294. DOI: 10.1590/01036440201902422.

12. L Darriba I, Cabirta Melon P, Garcia Sartal A, et al. Influence of treatment duration on the efficacy of at-home bleaching with daytime application: a randomized clinical trial. Clin oral investigations 2018;23(8):3229-3237. DOI: 10.1007/s00784-0182744-z.

13. ZARoNe F, LeoNe R, Di Mauro Ml, et al. No-preparation ceramic veneers: a systematic review. J Osseointegration 2018;10(1):17-22.

14. Schmidt KK, Chiayabutr Y, Phillips KM, et al. Influence of preparation design and existing condition of tooth structure on load to failure of 
ceramic laminate veneers. J Prosthet Dent 2011;105(6):374-382. DOI: 10.1016/S0022-3913(11)60077-2.

15. Gurel G, Sesma N, Calamita MA, et al. Influence of enamel preservation on failure rates of porcelain laminate veneers. Int J Periodontics \& Restor Dent 2013;33(1):31-39. DOI: 10.11607/prd.1488.

16. Radz GM. Minimum thickness anterior porcelain restorations. Dental Clin North Am 2011;55(2):353-370. DOI: 10.1016/j.cden.2011.01.006.

17. da Costa DC, Coutinho M, de Sousa AS, et al. A meta-analysis of the most indicated preparation design for porcelain laminate veneers. J Adhes Dent 2013;15(3):215-220. DOI: 10.3290/j.jad.a29587.

18. Hong N, Yang $\mathrm{H}$, Li J, et al. Effect of preparation designs on the Prognosis of porcelain laminate veneers: a systematic review and meta-analysis. Operative Dent 2017;42(6):E197-E213. DOI: 10.2341/16390-L.

19. Calamia JR. The current status of etched porcelain veneer restorations. J Philipp Dent Assoc 1996;47(4):35-41.

20. De Boever JA, McCall WD Jr, Holden S, et al. Functional occlusal forces: an investigation by telemetry. J Prosthet Dent 1978;40(3):326-333. DOI: 10.1016/0022-3913(78)90042-2.

21. Zarone F, Apicella D, Sorrentino R, et al. Influence of tooth preparation design on the stress distribution in maxillary central incisors restored by means of alumina porcelain veneers: a 3D-finite element analysis. Dent Mater 2005;21(12):1178-1188. DOI: 10.1016/j.dental.2005. 02.014 .

22. Alhekeir DF, Al-Sarhan RA, Al Mashaan AF. Porcelain laminate veneers: clinical survey for evaluation of failure. Saudi Dent J 2014;26(2):63-67. DOI: 10.1016/j.sdentj.2014.02.003.

23. Borba $M$, de Araújo $M D$, de Lima $E$, et al. Flexural strength and failure modes of layered ceramic structures. Dent Mater 2011;27(12): 1259-1266. DOI: 10.1016/j.dental.2011.09.008.

24. Seghi RR, Daher T, Caputo A. Relative flexural strength of dental restorative ceramics. Dent Mater 1990;6(3):181-184. DOI: 10.1016/0109-5641(90)90026-B.

25. Jones DW. The strength and strengthening mechanisms of dental ceramics. In: Mclean JW, ed. Dental ceramics: procedings of the first international symposium on ceramics. Chicago: Quintessence; 1983.

26. Turgut $S$, Bagis $B, A y a z E A$. Achieving the desired colour in discoloured teeth, using leucite-based CAD-CAM laminate systems. J Dent 2014;42(1):68-74. DOI: 10.1016/j.jdent.2013.10.018.

27. Kihn PW, Barnes DM. The clinical evaluation of porcelain veneer: a 48-month clinical evaluation. J Am Dent Assoc 1998;29(6): 211-221.

28. Clyde JS, Gilmour A. Porcelain veneer: a preliminary review. Br Dent J 1998;164(1):9-14. DOI: 10.1038/sj.bdj.4806328.

29. Peumans $M$, Van Meerbeek $B$, Lambrechts $P$, et al. Porcelain veneers: a review of the literature. J Dent 2000;28(3):163-177. DOI: 10.1016/ S0300-5712(99)00066-4.

30. Crispin BJ. Expanding the application of facial ceramic veneers. J Calif Dent Assoc 1993;21(6):43-54.

31. Christenses GJ. Veneering of teeth: state of the art. Dent Clin North Am 1985;29:373-391.

32. Arcari GM, Gil AMD, Baratieri LN, et al. Facetas esteticas com resinas compostas. Rev Gaucha Odont 1991;39:103-108.

33. Birnbaum NS. Heat-tempered composite resin laminate veneers in current opinion in cosmetic dentistry. 2nd ed. Philadelphia PA: Current Science; 1994.

34. Albers HF. Tooth-Colored Restoratives. Cotati: Alta Books; 1985.
35. Fahi NJ, Denehy GE, Jackson RD. Protocol for predictable restoration of anterior teeth with composite resins. Pract Periodont Aesthet Dent 1995;7(8):13-21.

36. Aldaij $M$, Alshehri T, Alzeer A, et al. Patient satisfaction with dental appearance and treatment desire to improve esthetics. J Oral Health Comm Dent 2018;12(3):90-95. DOI: 10.5005/jp-journals-10062-0033.

37. Akarslan ZZ, Sadik B, Erten H, et al. Dental esthetic satisfaction, received and desired dental treatments for improvement of esthetics. Indian J Dental Res 2009;20(2):195-200. DOI: 10.4103/09709290.52902.

38. Majed DA, May AA, Raneem IA. Satisfaction of a saudi population with their smiles. Adv Dent \& Oral Health 2017;3(3):1-7.

39. Thiyagarajan A, Kumar D. Dental esthetics: perception from future dental professionals. Acta Sci Dental Sci 2018;2(4):03-05.

40. Granell-Ruiz M, Fons-Font A, Labaig-Rueda C, et al. A clinical longitudinal study 323 porcelain laminate veneers. Period of study from 3 to 11 years. Med Oral Patol Oral Cir Bucal 2010;3:12. DOI: 10.4317/medoral.15.e531.

41. Beier US, Kapferer I, Burtscher D, et al. Clinical performance of porcelain laminate veneers for up to 20 years. Int J Prosthodontics 2012;25(1):79-85.

42. Burke FT. Survival rates for porcelain laminate veneers with special reference to the effect of preparation in dentin: a literature review. J Esthetic Restor Dent 2012;24(4):257-265. DOI: 10.1111/j.17088240.2012.00517.x.

43. Castelnuovo J, Tjan AH, Phillips $\mathrm{K}$, et al. Fracture load and mode of failure of ceramic veneers with different preparations. J Prosthet Dent 2000;83(2):171-180. DOI: 10.1016/S0022-3913(00)80009-8.

44. Chen JH, Shi CX, Wang M, et al. Clinical evaluation of 546 tetracyclinestained teeth treated with porcelain laminate veneers. J Dent 2005;33(1):3-8. DOI: 10.1016/j.jdent.2004.06.008.

45. Fradeani $M$, Redemagni $M$, Corrado M. Porcelain laminate veneers: 6 to 12 -year clinical evaluation-a retrospective study. Int J Periodontics \& Restor Dent 2005;25(1):9-17.

46. Petridis HP, Zekeridou A, Malliari M, et al. Survival of ceramic veneers made of different materials after a minimum follow-up period of five years: a systematic review and meta-analysis. Eur J Esthet Dent 2012;7(2):138-152.

47. Shaini FJ, Shortall AC, Marquis PM. Clinical performance of porcelain laminate veneers. A retrospective evaluation over a period of 6.5 years. J Oral Rehabilitation 1997;24(8):553-559. DOI: 10.1046/j.13652842.1997.00545.x

48. Land MF, Hopp CD. Survival rates of all-ceramic systems differ by clinical indication and fabrication method. J Evid Based Dental Pract 2010;10(1):37-38. DOI: 10.1016/j.jebdp.2009.11.013.

49. Meijering AC, Creugers NH, Roeters FJ, et al. Survival of three types of veneer restorations in a clinical trial: a 2.5-year interim evaluation. J Dent 1998;26(7):563-568. DOI: 10.1016/S0300-5712(97)00032-8.

50. Alfouzan A, Al-Sanie AA, Al-Dhafiri RA. Arab societal awareness of dental veneers. J Contemporary Dental Pract 2018;19(3):257-261. DOI: 10.5005/jp-journals-10024-2248.

51. Asaad RS, Alshwaer AA, Alahmadi SA, et al. Awareness of the population about ceramic laminate veneers in Saudi Arabia. Curr Sci Int 2019;8(1):42-46.

52. Sowmya S, Sunitha $S$, Dhakshaini MR, et al. Esthetics with veneers: a review. Int J Dental Health Concerns 2015;1(1):1-5. DOI: 10.15713/ins. ijdhc.11. 


\section{Appendix: Questionnaire}

(Kindly answer all questions)

Name:

Age:

Gender:

Nationality:

Area of residence:

1. Are you satisfied with the current dental esthetic treatment? Yes/No

2. What is the cause for dissatisfaction with esthetics?
a. Malposition
b. Stains
c. Missing teeth
d. Fractured teeth
e. Other reasons
f. No specific reason

3. Have you undertaken any previous dental esthetic treatment? Yes/No

4. If yes to question 3 , then what type of treatment was obtained?
a. Composite buildup
b. Bleaching
c. Veneers
d. Prepless veneers (lumineers)

5. Which type of esthetic dental treatment is preferred?
a. Temporary
b. Permanent

6. Did you encounter any complications after getting the esthetic treatment done? Yes/No

7. What was the type of complication?
a. Sensitivity
b. Bleeding from gums
c. Bad odor
d. Swelling
e. Broken restoration 